\title{
Determination of the Permeation and Penetration of Flurbiprofen into Cadaveric Human Pharynx
} Tissue

\author{
Rob Turner' \\ Sean Robert Wevrett (iD) \\ Suzanne Edmunds (iD) \\ Marc B Brown ${ }^{1,2}$ \\ Robert Atkinson ${ }^{3}$ \\ Oluwajoba Adegoke ${ }^{3}$ \\ Anuradha Kulasekaran ${ }^{4}$ \\ Tim Shea ${ }^{5}$ \\ 'MedPharm Ltd, Surrey Research Park, \\ Guildford, UK; ${ }^{2}$ The Research Centre in \\ Topical Drug Delivery and Toxicology \\ (TDDT), University of Hertfordshire, \\ College Lane Campus, Herts, UK; ${ }^{3}$ Medical \\ Science, Reckitt Benckiser, Hull, UK; \\ ${ }^{4}$ Medical Affairs, Reckitt Benckiser, Slough, \\ UK; ${ }^{5}$ Medical Science, Reckitt Benckiser, \\ Parsippany, NJ, USA
}

This article was published in the following Dove Press journal: Clinical Pharmacology: Advances and Applications

\begin{abstract}
Objective: Flurbiprofen $8.75 \mathrm{mg}$ spray and lozenge have a rapid onset of action for sore throat relief, suggesting local action, although tissue penetration and the mechanism of local relief have not been determined. This investigation aimed to quantify the permeation and penetration of flurbiprofen, applied as local pharmaceutical forms, into full-thickness cadaveric human mucosal pharynx tissue, representing the clinical scenario as far as possible.
\end{abstract}

Methods: A validated high-performance liquid chromatography method quantified the permeation and penetration of flurbiprofen (spray and lozenge formulations) into human cadaveric pharynx tissue using a micro Franz cell model mimicking physiological and anatomical conditions. Full-thickness mucosal pharynx tissue, consisting of oral epithelium, basement membrane, and lamina propria, was utilized to imitate the in vivo setting. Flurbiprofen was analyzed on the surface of the pharynx tissue, within the pharynx tissue and in receiver fluid, over 60 mins.

Results: Flurbiprofen was detected in receiver fluid from 10 mins following spray application and was quantifiable from 20 mins. Flurbiprofen from lozenge was detected from 10 mins and was above the limit of quantitation in receiver fluid from 40 mins. Flurbiprofen recovered from the surface of the pharynx tissue was $24.45 \%$ and $8.48 \%$ of applied dose for spray and lozenge, respectively. Flurbiprofen recovered within pharynx tissue was $46.50 \%$ and $54.65 \%$ of applied dose for spray and lozenge, respectively. For flurbiprofen lozenge, recovery within pharynx tissue was 6-fold higher relative to recovery from the pharynx tissue surface.

Conclusion: Flurbiprofen from spray and lozenge formulations penetrated human cadaveric pharynx tissue, indicating that flurbiprofen can reach all layers of the pharynx mucosal tissue, including the underlying lamina propria, which contains blood vessels and nerve fibers that contribute to pain during sore throat. This suggests that flurbiprofen may have a local mechanism of action for sore throat, although this has yet to be determined.

Keywords: chromatography, high-pressure liquid, flurbiprofen, Franz diffusion cell, pharynx

\section{Plain Language Summary}

Sore throat (also called pharyngitis) describes pain due to inflammation of tissues at the back of the throat (oropharynx). Flurbiprofen is a non-steroidal anti-inflammatory drug that provides rapid and long-lasting relief (up to $6 \mathrm{hrs)} \mathrm{for} \mathrm{sore} \mathrm{throat} \mathrm{pain} \mathrm{when} \mathrm{used} \mathrm{as} \mathrm{a} \mathrm{throat}$ spray or lozenge.

This study examined delivery of flurbiprofen to the tissues at the back of the throat to better understand how the drug provides sore throat relief. An experimental
Correspondence: Anuradha Kulasekaran Reckitt Benckiser PLC, 103-105 Bath

Road, Slough SLI 3UH, UK

Tel +441753217800

Email anuradha.kulasekaran@rb.com 
model mimicked how flurbiprofen throat spray and lozenge would be applied to the pharynx, measuring the proportion of flurbiprofen reaching the surface of the pharynx, within the pharynx and in the receiver fluid of the model.

Flurbiprofen from throat spray was measurable in the receiver fluid 20 mins after application. In total, $24 \%$ of the flurbiprofen spray dose used in the experiment was found on the surface of the pharynx and $47 \%$ was found within the pharynx tissue.

Flurbiprofen from lozenge was quantifiable in the receiver fluid from 40 mins after it was applied. A small proportion of the dose of the lozenge $(8 \%)$ was found on the surface of the pharynx, while $55 \%$ was found within the pharynx tissue.

Flurbiprofen, in spray and lozenge formulations, penetrated full-thickness human cadaveric mucosal pharynx tissue. Therefore, it may be possible that flurbiprofen spray and lozenge provide sore throat relief by acting locally at the back of the throat; however, this has yet to be established.

\section{Introduction}

The throat (or pharynx) is exposed to a range of infectious and non-infectious factors that can cause pharyngeal inflammation (pharyngitis), ${ }^{1,2}$ commonly described by patients as sore throat. ${ }^{3,4}$ The structure of throat tissue comprises an oral epithelium (approximately 40-50 cells deep), which overlays the basement membrane, beneath which is found the lamina propria, which borders the submucosa. ${ }^{5-9}$ The blood vessels and nerve fibers that contribute to the pain and edema that are characteristic of inflammation $^{10,11}$ are located throughout throat tissue, including the oral epithelium and the underlying lamina propria. ${ }^{6-9}$ Inflammatory mediators released in response to infectious or non-infectious factors in the throat exert their effects on these nerve fibers in the layers of throat tissue, ${ }^{1,12}$ resulting in the pain and discomfort of sore throat, which can be accompanied by difficulty swallowing and swollen throat. ${ }^{1-4,13}$

Sore throat, which can last for 3-7 days, ${ }^{14}$ is common and is experienced by $54 \%$ of people each year according to a survey conducted in Europe and Asia. ${ }^{15}$ Targeting the area of pain due to inflammation in the throat tissue with pharmaceuticals that deliver an active ingredient at this site is a well-accepted approach for treating sore throat. ${ }^{4,13,16-18}$ Locally applied non-steroidal anti-inflammatory drugs (NSAIDs), which exert both analgesic and anti-inflammatory effects, have been shown to relieve the symptoms of sore throat. $^{4,19-21}$ The NSAID flurbiprofen has been shown to be effective for the relief of pain of sore throat. ${ }^{4,19-23}$ The efficacy of flurbiprofen spray has been evaluated in three randomized controlled studies in post-tonsillectomy pain and shown to be effective. ${ }^{24-26}$ Flurbiprofen is available in spray and lozenge formulations at a low dose for relief of the sore throat pain due to inflammation. Local delivery of lowdose flurbiprofen may reduce the potential for systemic adverse effects compared with oral high-dose NSAIDs. ${ }^{27}$ Flurbiprofen (low-dose lozenge and spray) for sore throat was developed to adhere to the principle of utilizing the lowest possible dose of medication to achieve an optimal efficacy/safety profile. ${ }^{28}$

The absorption of flurbiprofen in the oropharyngeal region is still not well understood. Although it is known that flurbiprofen is absorbed across the cells of the buccal mucosa, ${ }^{29,30}$ there are currently no studies published that have determined the extent of its penetration into the tissue of the pharynx.

The Franz cell technique is a well-established methodology, and Franz diffusion cells are routinely used in transdermal drug delivery research/membrane penetration experiments. ${ }^{31-34}$ Specific methodology has been developed utilizing Franz diffusion cells to quantify flurbiprofen penetration through human pharynx tissue using a validated high-performance liquid chromatography (HPLC) method. ${ }^{35}$

Although the extent of penetration into the pharynx tissue has not yet been determined, the rapid onset of action of flurbiprofen spray and lozenge suggests they may work locally. ${ }^{16,19-21}$ The aim of this investigation, therefore, was to quantify the permeation and penetration of locally delivered flurbiprofen $8.75 \mathrm{mg}$ spray and lozenge formulations into full-thickness human mucosal pharynx tissue. Information on the penetration of flurbiprofen into the pharynx tissue would enable future research to understand the local effect of the drug in providing the rapid pain relief observed clinically. ${ }^{16,19-21}$

\section{Materials and Methods}

This investigation was conducted by MedPharm Ltd. (Guildford, UK) in accordance with the International Conference on Harmonisation (ICH) Pharmaceutical Quality System Q10, 2008. ${ }^{36}$ The permeation and penetration of flurbiprofen (from flurbiprofen $8.75 \mathrm{mg}$ spray and flurbiprofen $8.75 \mathrm{mg}$ lozenge formulations) into human pharynx tissue was tested in a micro Franz diffusion cell model $^{33}$ to mimic the physiological and anatomical conditions of the human pharynx tissue in situ. The bichambered micro Franz diffusion cell (Figure 1) had an 


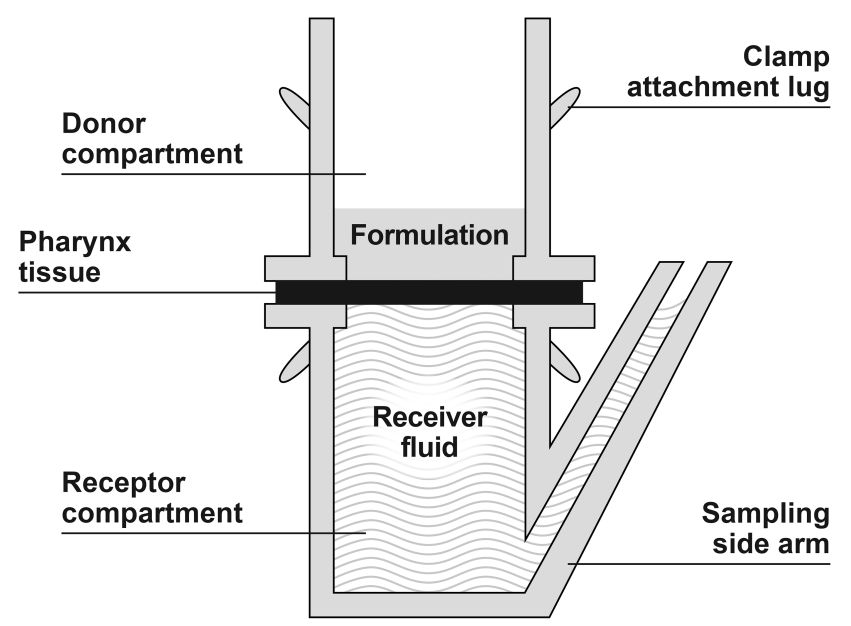

Figure I Schematic representation of a Franz diffusion cell.

average surface area of $0.07 \mathrm{~cm}^{2}$ and a volume of approximately $2.0 \mathrm{~mL}$.

Human pharynx tissue was ethically sourced from cadavers by a pathologist (Ethical Tissue, University of Bradford, UK: Research Ethics Committee reference 220367). The tissue was then stored and supplied frozen, after which the tissue was thawed and cut to approximately $0.5-1.0 \mathrm{~cm}^{2}$ prior to mounting in the Franz diffusion cell. No further manipulation of the tissue was performed prior to experimentation. The receiver fluid was phosphate-buffered saline (PBS) and the extraction fluid was 90:10 (volume:volume) ethanol: water. Flurbiprofen was quantitated in receiver and extraction fluids by HPLC using the LC2030C HPLC system (Shimadzu UK Ltd., Milton Keynes, UK) and Empower 3 Data Processing Software (Waters UK, Elstree, UK). The validation of the HPLC method and development of the receiver fluid and extraction method and fluid have been reported previously. ${ }^{35}$

\section{Test Formulations}

The test formulations manufactured and supplied by Reckitt Benckiser were Strefen flurbiprofen $8.75 \mathrm{mg}$ honey and lemon lozenge (manufactured in Nottingham, UK; also known as Strepsils Intensive, Strepfen Intensive, Strepsils Max Pro, Strefen Intensive, Benactiv Gola, Dobendan Direkt and Graneodin F) and Benactivdol Gola flurbiprofen $8.75 \mathrm{mg} /$ dose throat spray (manufactured in Bangplee, Thailand; also known as Strepsils Intensive, Strepfen Intensive, Benactiv Gola, and Dobendan Direkt).

\section{Permeation and Penetration Experiment}

Following a small-scale investigation to optimize the experimental parameters, a larger scale experiment $(\mathrm{n}=6$ per formulation) was conducted to investigate the permeation and penetration of flurbiprofen through human pharynx tissue using the Franz diffusion cell. Human pharynx tissue was mounted between the donor compartment (containing the spray or lozenge formulation) and receiver compartment (containing the receiver fluid) of the Franz diffusion cell (Figure 1). An additional Franz diffusion cell was mounted with pharynx tissue that was not dosed with formulation to ensure there was no interference on the HPLC analysis arising from the tissue during the permeation experiment.

Flurbiprofen equivalent to one dose of spray or lozenge was applied to the donor compartment of the Franz diffusion cell. For the $8.75 \mathrm{mg}$ spray formulation, three spray actuations were used, equivalent to one dose. ${ }^{37}$ Previous studies have indicated that flurbiprofen spray delivers an accurate and reproducible amount per spray. ${ }^{18}$ Flurbiprofen doses for the experiment were selected to replicate the anticipated clinical residency time. ${ }^{30,38,39}$ For the $8.75 \mathrm{mg}$ lozenge formulation, one lozenge was dissolved in $7.5 \mathrm{~mL}$ of receiver fluid, and a $15 \mu \mathrm{L}$ aliquot of this solution was used. The dose for the lozenge was calculated to mimic in vivo conditions using the average size of human pharynx tissue (35.9 $\mathrm{cm}^{2}$, calculated for the oropharynx and hypopharynx using information published previously) and saliva production $(0.75 \mathrm{~mL} / \mathrm{min}$ on average, about 10 mins for a lozenge to dissolve). ${ }^{40,41}$ This equated to doses of 187.73 (standard deviation $[\mathrm{SD}] \pm 171.22) \mu \mathrm{g}$ and $15.11(\mathrm{SD} \pm 0.09) \mu \mathrm{g}$ flurbiprofen applied to the pharynx tissue from the spray and lozenge formulations, respectively, as confirmed by HPLC. Samples of receiver fluid were removed at $10 \mathrm{~min}$ intervals from 0 to $60 \mathrm{mins}$.

Following the permeation experiment, flurbiprofen was then recovered from the surface and within the pharynx tissue using extraction fluid, as described previously. ${ }^{35}$ Three cotton swabs were used to recover flurbiprofen from the surface of the human pharynx tissue. The donor compartment was dismantled, and one dry cotton swab was used to remove any remaining flurbiprofen from the surface of the human pharynx tissue; a second cotton swab was immersed into extraction fluid and was used to swab the surface of the human pharynx tissue; a final dry swab was then used to swab the surface of the human pharynx tissue. All three swabs were placed into a glass vial with $2 \mathrm{~mL}$ of 
extraction fluid and the vial was shaken on an orbital shaker at room temperature for 16-20 hrs.

To recover flurbiprofen from within the human pharynx tissue, the sample was stored in a freezer overnight following the permeation experiment. The tissue was placed in a homogenizer vial (filled to approximately $75 \%$ capacity with beads) with $1 \mathrm{~mL}$ of extraction fluid and homogenized at 5,800 revolutions per minute (RPM) for $40 \mathrm{~s}$ at room temperature. The contents were emptied into a new glass vial. An additional $1 \mathrm{~mL}$ of extraction fluid was added to the empty tissue homogenizer vial, which was vortexed for $30 \mathrm{~s}$ and the contents were emptied into the glass vial. The vial was shaken on an orbital shaker at room temperature for 16-20 hrs. Following the extraction procedure, the extraction fluid was removed, centrifuged at 13,000 RPM (approximately 16,000 g) for 10 mins at room temperature and the supernatant was analyzed using the HPLC analytical method.

Flurbiprofen in the receiver fluid was also analyzed using the HPLC analytical method. Where recovered levels of flurbiprofen were consistently below the limit of quantitation (BLOQ) for all time points tested in the receiver fluid, the samples were concentrated approximately 10-fold (by pooling, evaporation, and reconstitution in a smaller volume).

\section{Statistical Analyses}

The percentage of flurbiprofen recovered from the surface and within the human pharynx tissue following application of the flurbiprofen throat spray and lozenge were calculated (mean, median, standard deviation, standard error of mean, $95 \%$ confidence interval $[\mathrm{CI}])$. Statistical comparisons were made between the percentage of flurbiprofen recovered from the surface and within the human pharynx using an unpaired $t$-test with Welch's correction for flurbiprofen lozenge, and an unpaired $t$-test for flurbiprofen spray. The independent $t$-test was selected as the comparison was between means of normally distributed independent samples with unequal variances.

\section{Results}

The permeation and penetration data are presented in Figure 2 and Table 1, including the cumulative amount of flurbiprofen (percentage of applied dose) which permeated through the pharynx tissue, and the total amount of flurbiprofen recovered from the human pharynx and receiver fluid. Following application of the spray, flurbiprofen was quantifiable in the receiver fluid from 20 mins, although its presence

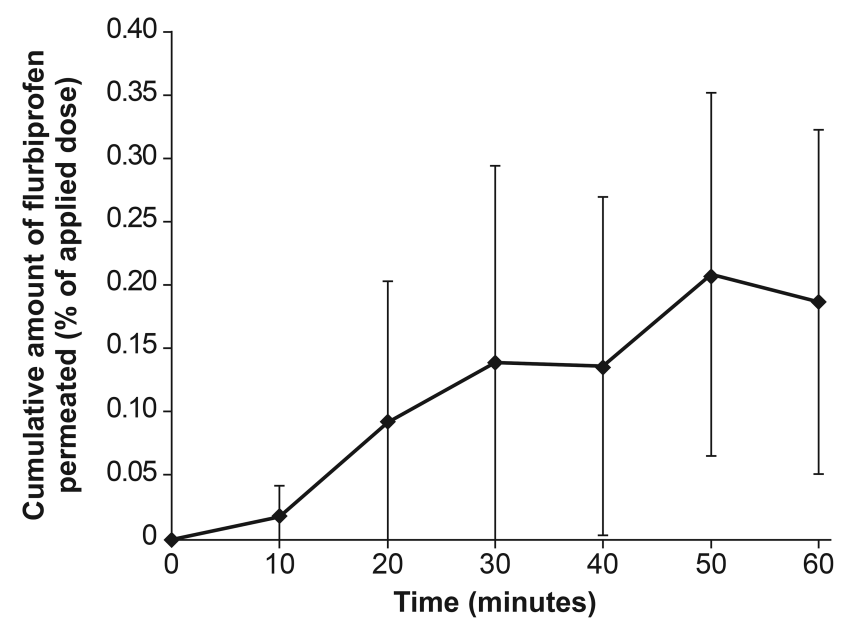

Figure 2 Cumulative amount of flurbiprofen (percentage of applied dose) permeated through human pharynx tissue and recovered from receiver fluid over time for flurbiprofen $8.75 \mathrm{mg}$ spray. Each value represents the mean \pm standard deviation of the results obtained in samples $(n=5$ replicates; I donor). Flurbiprofen in the receiver fluid was measured by high-performance liquid chromatography. Values for flurbiprofen in the receiver fluid for the lozenge formulation were below the level of quantitation and the data are therefore not shown.

was detected (BLOQ) from 10 mins onwards (Figure 2). The total amount of flurbiprofen present in the receiver fluid at 60 mins was $0.35( \pm 0.25) \mu \mathrm{g}(0.19 \%$ of applied dose) .

Following application of the lozenge, flurbiprofen was consistently at levels BLOQ in the receiver fluid (due to the dilution effect of mimicking in vivo conditions). After concentration, flurbiprofen was detected (signal-to-noise ratio was $>3$ ) from 10 mins onwards and was above the limit of quantitation (LOQ) in the receiver fluid from 40 mins, confirming that the flurbiprofen did penetrate through the pharynx tissue.

The amount of flurbiprofen recovered from the surface of the pharynx tissue was $45.91 \mu \mathrm{g}$ for spray $(24.45 \%$ of the applied dose) and $1.28 \mu \mathrm{g}$ for lozenge $(8.48 \%$ of the applied dose) (Table 1). The amount of flurbiprofen recovered from within the pharynx tissue was $87.30 \mu \mathrm{g}$ for spray ( $46.50 \%$ of applied dose) and $8.26 \mu \mathrm{g}$ for lozenge (54.65\% of applied dose) (Table 1). Significantly more flurbiprofen was recovered from within the pharynx tissue compared with the surface of the tissue for the lozenge $(p<0.05)$; however, no statistical difference was observed between the amount of flurbiprofen that was recovered within the pharynx tissue compared with the surface for the spray $(\mathrm{p}>0.05)$.

\section{Discussion}

The aim of this study was to quantify the permeation and penetration of a dose of flurbiprofen from $8.75 \mathrm{mg}$ spray 
Table I Permeation and Penetration. Experimental Results ( $\mathrm{N} \geq 3$ ), Presented with the Mean (Standard Deviation). Flurbiprofen in the Receiver Fluid Was Measured by High-Performance Liquid Chromatography

\begin{tabular}{|c|c|c|}
\hline & \multicolumn{2}{|l|}{ Formulation } \\
\hline & Lozenge & Spray \\
\hline Amount of flurbiprofen applied ( $\mu \mathrm{g})$ & $15.11(0.09)$ & $187.73(171.22)$ \\
\hline $\begin{array}{l}\text { Flurbiprofen Recovered from the Surface } \\
\text { of the Pharynx Tissue } \\
\text { Amount ( } \mu \mathrm{g}) \\
\text { Proportion of applied dose (\%) }\end{array}$ & $\begin{array}{l}1.28(0.40) \\
8.48(2.66)\end{array}$ & $\begin{array}{l}45.91(56.96) \\
24.45(30.34)\end{array}$ \\
\hline $\begin{array}{l}\text { Flurbiprofen Recovered from Within the } \\
\text { Pharynx Tissue } \\
\text { Amount ( } \mu \mathrm{g}) \\
\text { Proportion of applied dose (\%) }\end{array}$ & $\begin{array}{l}8.26(0.8 I) \\
54.65(5.35)\end{array}$ & $\begin{array}{l}87.30(58.65) \\
46.50(31.24)\end{array}$ \\
\hline $\begin{array}{l}\text { Flurbiprofen Present in the Receiver Fluid } \\
\text { Amount ( } \mu \mathrm{g}) \\
\text { Proportion of applied dose }(\%)\end{array}$ & $\begin{array}{l}\text { Present, but } \\
\text { BLOQ* } \\
\text { N/A* }\end{array}$ & $\begin{array}{l}0.35(0.25) \\
0.19(0.14)\end{array}$ \\
\hline
\end{tabular}

Note: *BLOQ, below level of quantitation $(<0.045 \mu \mathrm{g} / \mathrm{mL})$. Abbreviation: N/A, not applicable.

and lozenge formulations into full-thickness human pharynx tissue, using an ex vivo model designed to replicate the clinical scenario of absorption into pharyngeal tissue. The dosing concentration of flurbiprofen was determined to mimic real-life human use of the lozenge and replicated for spray. ${ }^{30,38,39}$ There are several different models for assessing the oral absorption of drugs; however, a key limitation is that contact time in the oral cavity may not be a true reflection of what takes place in the in vivo setting. ${ }^{42}$ The results reported here showed that a fraction of the dose from the $8.75 \mathrm{mg}$ spray and lozenge formulations applied to the human pharynx tissue permeated and penetrated the layers of pharynx tissue. For flurbiprofen lozenge, recovery within the pharynx tissue was 6-fold higher relative to recovery from the pharynx tissue surface. The numerically higher recovery of flurbiprofen from the surface of the pharynx tissue after application of the spray compared with the lozenge $(24.5 \%$ and $8.5 \%$, respectively) may be due to the larger amount of flurbiprofen applied to the same surface area of tissue from the spray formulation compared with the lozenge. The low level of flurbiprofen from the lozenge formulation in the receiver fluid was likely a consequence of the dilution effect in the efforts to replicate the in vivo conditions. The method utilized detected flurbiprofen in the receiver fluid after 10 mins (signal-to-noise ratio $>3$ ), indicating flurbiprofen had successfully started to permeate through the human pharynx tissue. According to Desimoni (2015), ${ }^{43}$ a signal-to-noise ratio $\geq 3$ indicates presence of the analyte in the test sample with a probability larger than $99 \%$.

Although this study utilized a small number of samples, the investigation demonstrated that flurbiprofen permeated full-thickness mucosal pharynx tissue. During the sucking of the lozenge in mouth or the use of a spray, it is expected that there will be a constant contact of a certain amount of flurbiprofen via saliva in the pharyngeal mucosa. This local penetration may contribute to the rapid onset of pain relief observed by patients taking flurbiprofen lozenge or spray; however, further research is required to confirm the basis for the onset of local action.

It is not practical to assess drug permeability into human pharynx non-invasively in an in vivo setting. Thus, this ex vivo model was specifically designed to represent a clinical scenario as much as possible. ${ }^{35}$ The full-thickness pharynx mucosal tissue consisting of epithelial, basement membrane, and lamina propria from human cadavers was used. This is one of the strengths of this investigation compared with an in vitro synthetic model or other animal tissue; the use of human tissue would match more closely the permeation of flurbiprofen in vivo and the architecture of the pharynx tissue would remain intact. Large inter-individual variation has been reported with human tissue samples (markedly larger than with Sprague Dawley rat skin) in a study using the Franz diffusion cell method to determine the permeation rate of flurbiprofen through human abdominal skin. ${ }^{44}$ This variation among human skin specimens has been shown to be due to differences in age, race, and anatomical donor site. ${ }^{44}$ In addition, previous studies have used synthetic membranes to determine the permeation of flurbiprofen or ibuprofen gel; however, although easily resourced, inexpensive, and structurally simpler, they do not reflect what may happen in vivo. ${ }^{32,45,46}$ An important limitation of our study was the use of cadaver tissue, which may result in drug penetration speed that does not truly reflect live tissue, where a blood supply is present. In addition, the absence of inflammation and the lack of a mucosal barrier may modify drug penetration. As a result, the findings may not fully reflect what takes place in a clinical setting and should be interpreted accordingly.

During this investigation, the application of the two formulations was designed to replicate real-life application 
by patients. Although this resulted in different absolute amounts of drug being applied to the pharynx tissue, likely to be the cause of the difference in the quantity of flurbiprofen recovered from the surface of and within the pharynx tissue, complicating direct comparison between spray and lozenge, this was not the main aim of the investigation. Full mass balance was not conducted for the current investigation to verify the incomplete recovery (by swabbing all surfaces that the receiver fluid is not in direct contact with and ensuring the total amount of drug adds up to approximately $100 \%$ ). In line with the product formulations and aim of the investigation, only one test concentration of flurbiprofen was used, with the intention of mimicking usage by patients according to the posology of the drug. Further studies are needed to determine any effects of different concentrations of flurbiprofen on penetration into the pharynx.

A further limitation of the study is the absence of a specific control, such as a different tissue or model, or the use of unformulated flurbiprofen. As there were no suitable alternative marketed products available, it was not possible to use a positive formulation control (where delivery of flurbiprofen would be expected) in this study.

Franz diffusion cells were utilized due to their routine application in transdermal drug delivery research/membrane penetration experiments, and the availability of specific methodology using Franz diffusion cells for the quantitation of flurbiprofen penetration through human pharynx tissue. ${ }^{35}$ Several studies have shown that flurbiprofen is absorbed across the cells of the buccal mucosa. ${ }^{29,30}$ Pharmacokinetic studies show that flurbiprofen is absorbed via the buccal cavity from $1 \mathrm{~min}^{30}$ and is still detectable in the mouth and oropharyngeal region at 120 mins post dose. ${ }^{38}$ These results highlight the oropharyngeal mucosa region as a site of absorption of flurbiprofen. Comparing the penetration of flurbiprofen spray and lozenge in different, relevant tissues and models may enable an even more complete view of the absorption characteristics of flurbiprofen.

Finally, another possible limitation is that a majority of the results from the investigation were close to the LOQ of the method. The LOQ in this investigation was $0.045 \mu \mathrm{g} /$ $\mathrm{mL}$, which is slightly lower than other studies using HPLC, which have reported a LOQ of $0.10 \mu \mathrm{g} / \mathrm{mL}^{47}$ and $0.578 \mu \mathrm{g} / \mathrm{mL} .{ }^{48}$ However, more sensitive approaches such as liquid chromatography-mass spectrometry have reported a LOQ for flurbiprofen as low as $7.4 \mathrm{pg} / \mathrm{mL}{ }^{49}$ Therefore, in retrospect, a more sensitive method could have been used. Additionally, the method for evaporating and reconstituting the lozenge receiver fluid samples was not validated in the current investigation. Although outside of the scope of this study, future studies assessing effective formulations for the treatment of sore throat would be of great benefit to clinical decision-makers.

\section{Conclusion}

This is the first study to report the permeation and penetration of flurbiprofen across full-thickness human mucosal pharynx tissue, relevant to the site of delivery of flurbiprofen via lozenge and spray used in the treatment of sore throat symptoms. The possibility of using this methodology to investigate and predict human pharyngeal absorption is thereby supported. The results show that flurbiprofen from $8.75 \mathrm{mg}$ spray and lozenge formulations penetrates into the layers of whole cadaveric human pharynx tissue. These data aid in the understanding of flurbiprofen absorption into pharyngeal tissue as the purpose of development of topical sore throat products is to prolong local delivery of the drug at the inflamed site where it is most needed. The penetration data imply that passive diffusion (penetration) is possible in mucosal pharynx tissue following topical application. This evidence is key to support exploration of local drug effect in further studies.

\section{Abbreviations}

BLOQ, below limit of quantitation; CI, confidence interval; HPLC, high-performance liquid chromatography; ICH, International Conference on Harmonisation; LOQ, limit of quantitation; N/A, not applicable; NSAID, non-steroidal anti-inflammatory drug; PBS, phosphate-buffered saline; RPM, revolutions per minute; SD, standard deviation.

\section{Acknowledgments}

The authors gratefully acknowledge the contribution of John Farrah of Reckitt Benckiser. Medical writing assistance was provided by Elements Communications Ltd. (Westerham, UK), which was supported by Reckitt Benckiser.

\section{Author Contributions}

All authors met the International Committee of Medical Journal Editors criteria for authorship. All authors contributed to data analysis, drafting and revising the article, gave final approval of the version to be published, and agree to be accountable for all aspects of the work. 


\section{Funding}

This study was supported by Reckitt Benckiser.

\section{Disclosure}

Robert Atkinson, Oluwajoba Adegoke, Anuradha Kulasekaran and Tim Shea are employees of Reckitt Benckiser. Rob Turner, Sean Robert Wevrett, Suzanne Edmunds, and Marc Brown are employees of MedPharm Ltd. The authors report no other conflicts of interest in this work.

\section{References}

1. Eccles R. Mechanisms of symptoms of the common cold and influenza. Br J Hosp Med (Lond). 2007;68(2):71-75. doi:10.12968/ hmed.2007.68.2.22824

2. Renner B, Mueller CA, Shephard A. Environmental and non-infectious factors in the aetiology of pharyngitis (sore throat). Inflamm Res. 2012;61(10):1041-1052. doi:10.1007/s00011-0120540-9

3. Schachtel BP, Fillingim JM, Beiter DJ, Lane AC, Schwartz LA. Subjective and objective features of sore throat. Arch Intern Med. 1984;144(3):497-500. doi:10.1001/ archinte. 1984.00350150081026

4. Schachtel B, Shephard A, Schachtel E, Lorton MB, Shea T, Aspley S. Qualities of Sore Throat Index (QuaSTI): measuring descriptors of sore throat in a randomized, placebo-controlled trial. Pain Manag. 2018;8(2):85-94. doi:10.2217/pmt-2017-0041

5. Shojaei AH. Buccal mucosa as a route for systemic drug delivery: a review. J Pharm Sci. 1998;1(1):15-30.

6. Harris D, Robinson JR. Drug delivery via the mucous membranes of the oral cavity. J Pharm Sci. 1992;81(1):1-10. doi:10.1002/jps.2600 810102

7. Nicolazzo JA, Finnin BC. In vivo and in vitro models for assessing drug absorption across the buccal mucosa. In: Ehrhardt C, Kim KJ, editors. Drug Absorption Studies. Biotechnology: Pharmaceutical Aspects. Boston: Springer; 2008:89-111.

8. Squier CA, Kremer MJ, Biology of oral mucosa and esophagus. J Natl Cancer Inst Monogr. 2001;29:7-15. doi:10.1093/oxfordjournals.jncimonographs.a003443

9. Squier C, Brogden KA. Human Oral Mucosa: Development, Structure and Function. Oxford: Wiley-Blackwell; 2011.

10. Funk CD. Prostaglandins and leukotrienes: advances in eicosanoid biology. Science. 2001;294(5548):1871-1875. doi:10.1126/ science.294.5548.1871

11. Ricciotti E, FitzGerald GA. Prostaglandins and inflammation. Arterioscler Thromb Vasc Biol. 2011;31(5):986-1000. doi:10.1161/ ATVBAHA.110.207449

12. Oxford JS, Leuwer M. Acute sore throat revisited: clinical and experimental evidence for the efficacy of over-the-counter AMC/ DCBA throat lozenges. Int J Clin Pract. 2011;65(5):524-530. doi:10.1111/j.1742-1241.2011.02644.x

13. Aspley S, Shephard A, Schachtel E, Sanner K, Savino L, Schachtel B. Efficacy of flurbiprofen $8.75 \mathrm{mg}$ lozenge in patients with a swollen and inflamed sore throat. Curr Med Res Opin. 2016;32(9):1529-1538. doi:10.1080/03007995.2016.1187119

14. Spinks A, Glasziou PP, Del Mar CB. Antibiotics for sore throat. Cochrane Database Syst Rev. 2013;11:CD000023.

15. Addey D, Shephard A. Incidence, causes, severity and treatment of throat discomfort: a four-region online questionnaire survey. $B M C$ Ear Nose Throat Disord. 2012;12:9. doi:10.1186/1472-6815-12-9
16. Schachtel B, Aspley S, Shephard A, et al. Onset of action of a lozenge containing flurbiprofen $8.75 \mathrm{mg}$ : a randomized, double-blind, placebo-controlled trial with a new method for measuring onset of analgesic activity. Pain. 2014;155(2):422-428. doi:10.1016/j.pain.2013.11.001

17. Essack S, Bell J, Shephard A. Community pharmacists - leaders for antibiotic stewardship in respiratory tract infection. $J$ Clin Pharm Ther. 2018;43(2):302-307. doi:10.1111/jcpt.2018.43.issue-2

18. Veale D, Shephard A, Adams V, Lidster C. Comparison of the characteristics and performance of flurbiprofen $8.75 \mathrm{mg}$ spray for sore throat. Curr Drug Deliv. 2017;14(5):725-733. doi:10.2174/ 1567201813666161205155830

19. de Looze F, Russo M, Bloch M, et al. Efficacy of flurbiprofen $8.75 \mathrm{mg}$ spray in patients with sore throat due to an upper respiratory tract infection: a randomised controlled trial. Eur J Gen Pract. 2016;22(2):111-118. doi:10.3109/13814788.2016.1145650

20. Radkova E, Burova N, Bychkova V, DeVito R. Efficacy of flurbiprofen $8.75 \mathrm{mg}$ delivered as a spray or lozenge in patients with sore throat due to upper respiratory tract infection: a randomized, non-inferiority trial in the Russian Federation. $J$ Pain Res. 2017;10:1591-1600. doi:10.2147/JPR

21. Schachtel B, Aspley S, Shephard A, Schachtel E, Lorton MB, Shea T. Onset of analgesia by a topically administered flurbiprofen lozenge: a randomised controlled trial using the double stopwatch method. $\mathrm{Br}$ J Pain. 2018;12(4):208-216. doi:10.1177/2049463718756152

22. Sefia E, Mann A, Lambkin R, et al. Flurbiprofen lozenges rapidly reduce levels of the inflammatory mediator prostaglandin $\mathrm{E}$ in human respiratory cells in vitro. Poster presented at: Annual Scientific Meeting of the British Pain Society; April 24-27, 2007; Glasgow, UK.

23. de Looze F, Shephard A, Smith AB. Locally delivered flurbiprofen $8.75 \mathrm{mg}$ for treatment and prevention of sore throat: a narrative review of clinical studies. J Pain Res. 2019;12:3477-3509. doi:10.2147/JPR.S221706

24. Muderris T, Gul F, Yalciner G, Babademez MA, Bercin S, Kiris M. Oral flurbiprofen spray for posttonsillectomy pain. Otolaryngol Head Neck Surg. 2016;155:166-172. doi:10.1177/0194599816637865

25. Muderris T, Tezcan G, Sancak M, Gul F, Ugur G. Oral flurbiprofen spray for postoperative sore throat and hoarseness: a prospective, randomized, double-blind, placebo-controlled study. Minerva Anestesiol. 2019;85(1):21-27. doi:10.23736/S0375-9393.18.12703-9

26. Türk B, Akpinar M, Erol ZN, Kaya KS, Ünsal O, Coşkum BU. The effect of flurbiprofen oral spray and ibuprofen vs ibuprofen alone on postoperative tonsillectomy pain: an open, randomised, controlled trial. Clin Otolaryngol. 2018;43:835-840. doi:10.1111/coa.13058

27. Barkin RL. The pharmacology of topical analgesics. Postgrad Med. 2013;125(4Suppl. 1):7-18. doi:10.1080/00325481.2013.1110566911

28. Imberti R, De Gregori S, Lisi L, Navarra P. Influence of the oral dissolution time on the absorption rate of locally administered solid formulations for oromucosal use: the flurbiprofen lozenges paradigm. Pharmacology. 2014;94(3-4):143-147. doi:10.1159/0003 67663

29. Barsuhn CL, Olanoff LS, Gleason DD, Adkins EL, Ho NF. Human buccal absorption of flurbiprofen. Clin Pharmacol Ther. 1988;44 (2):225-231. doi:10.1038/clpt.1988.141

30. Gonzalez-Younes I, Wagner JG, Gaines DA, Ferry JJ, Hageman JM. Absorption of flurbiprofen through human buccal mucosa. $J$ Pharm Sci. 1991;80(9):820-823. doi:10.1002/jps.2600800903

31. Azzi C, Zhang J, Purdon CH, et al. Permeation and reservoir formation of 4-(methylnitrosamino)-1-(3-pyridyl)-1-butanone (NNK) and benzo[a]pyrene $(\mathrm{B}[\mathrm{a}] \mathrm{P})$ across porcine esophageal tissue in the presence of ethanol and menthol. Carcinogenesis. 2006;27(1):137-145. doi:10.1093/carcin/bgi173

32. Ng SF, Rouse JJ, Sanderson FD, Meidan V, Eccleston GM. Validation of a static Franz diffusion cell system for in vitro permeation studies. AAPS PharmSciTech. 2010;11(3):1432-1441. doi:10.1208/s12249010-9522-9 
33. Franz TJ. Percutaneous absorption on the relevance of in vitro data. J Invest Dermatol. 1975;64(3):190-195. doi:10.1111/1523-1747.ep12 533356

34. Ingram RJ, Bartlett $\mathrm{A}$, Brown MB, Marriott $\mathrm{C}$, Whitfield PJ. Penetration of human skin by the cercariae of Schistosoma mansoni: an investigation of the effect of multiple cercarial applications. $J$ Helminthol. 2003;77(1):27-31. doi:10.1079/JOH2002157

35. Turner R, Wevrett SR, Edmunds S, Brown M, Atkinson R, Shea T. Validation of an analytical method to quantify the permeation and penetration of flurbiprofen into human pharynx tissue. Biomed Chromatogr. 2019;33:e4499. doi:10.1002/bmc.4499

36. International Conference on Harmonisation of Technical Requirements for Registration of Pharmaceuticals for Human Use. ICH Harmonised tripartite guideline. pharmaceutical quality system Q10. Available from: https://www.ich.org/fileadmin/Public_Web_ Site/ICH_Products/Guidelines/Quality/Q10/Step4/Q10_Guideline. pdf. Accessed April 1, 2019..

37. Strefen ${ }^{\circledR}$ Direct (flurbiprofen $8.75 \mathrm{mg}$ ) Oromucosal Spray [summary of product characteristics]. Reckitt Benckiser; 2014.

38. Limb M, Connor A, Pickford M, et al. Scintigraphy can be used to compare delivery of sore throat formulations. Int $J$ Clin Pract. 2009;63(4):606-612. doi:10.1111/ijcp.2009.63.issue-4

39. Geisslinger G, Lotsch J, Menzel S, Kobal G, Brune K. Stereoselective disposition of flurbiprofen in healthy subjects following administration of the single enantiomers. Br J Clin Pharmacol. 1994;37(4):392-394. doi:10.1111/j.1365-2125.1994.tb04295.x

40. Walsh JH, Leigh MS, Paduch A, et al. Evaluation of pharyngeal shape and size using anatomical optical coherence tomography in individuals with and without obstructive sleep apnoea. J Sleep Res. 2008;17(2):230-238. doi:10.1111/j.1365-2869.2008.00647.x
41. Peres JC, Rouquette JL, Miočević O, Warner MC, Slowey PD, Shirtcliff EA. New techniques for augmenting saliva collection: bacon rules and lozenge drools. Clin Ther. 2015;37(3):515-522. doi:10.1016/j.clinthera.2015.02.015

42. Rathbone MJ, Hadgraft J. Absorption of drugs from the human oral cavity. Int $J$ Pharmaceutics. 1991;74(1):9-24. doi:10.1016/03785173(91)90403-B

43. Desimoni E, Brunetti B. About estimating the limit of detection by the signal to noise approach. Pharm Anal Acta. 2015;6:355.

44. Takeuchi H, Mano Y, Terasaka S, et al. Usefulness of rat skin as a substitute for human skin in the in vitro skin permeation study. Exp Anim. 2011;60(4):373-384. doi:10.1538/expanim.60.373

45. Ayoub RK, Murtaza G, Imran M, et al. Formulation and permeation kinetic studies of flurbiprofen gel. Trop J Pharm Res. 2015;14 (2):195-203. doi:10.4314/tjpr.v14i2.2

46. Hussain A, Khan GM, Jan SU, et al. Effect of olive oil on transdermal penetration of flurbiprofen from topical gel as enhancer. Pak J Pharm Sci. 2012;25(2):365-369.

47. Yilmaz B, Erdem AF. Determination of flurbiprofen in human plasma by high-performance liquid chromatography. J Chromatogr Sci. 2015;53(9):1443-1448. doi:10.1093/chromsci/bmv032

48. Akhlaq M, Khan GM, Wahab A, et al. A simple high-performance liquid chromatographic practical approach for determination of flurbiprofen. J Adv Pharm Technol Res. 2011;2(3):151-155. doi:10.4103/2231-4040.85529

49. Mano N, Narui T, Nikaido A, Goto J. Separation and determination of diastereomeric flurbiprofen acyl glucuronides in human urine by LC/ESI-MS with a simple column-switching technique. Drug Metab Pharmacokinet. 2002;17(2):142-149. doi:10.2133/dmpk.17.142

\section{Publish your work in this journal}

Clinical Pharmacology: Advances and Applications is an international, peer-reviewed, open access journal publishing original research, reports, reviews and commentaries on all areas of drug experience in humans. The manuscript management system is completely online and includes a very quick and fair peer-review system, which is all easy to use. Visit http://www.dovepress.com/testimonials.php to read real quotes from published authors.

Submit your manuscript here: https://www.dovepress.com/clinical-pharmacology-advances-and-applications-journal 